\title{
Dandelion prevents liver fibrosis, inflammatory response, and oxidative stress in rats
}

\author{
Alaaeldin Ahmed Hamza ${ }^{1,2^{*}}$ (D), Mona Gamel Mohamed ${ }^{1}$, Fawzy Mohamed Lashin ${ }^{1}$ and Amr Amin ${ }^{2,3^{*}}$
}

\begin{abstract}
Background: Liver fibrosis is the main contributor to the chronic liver-associated morbidity and mortality.

Purpose: The study was conducted to evaluate the effects of whole plant powder of dandelion (Taraxacum officinale) on liver fibrosis.
\end{abstract}

Methods: Liver fibrosis was induced by the oral administration of 20\% carbon tetrachloride (CCL4), twice a week for 8 weeks. Simultaneously, dandelion root extract $(500 \mathrm{mg} / \mathrm{kg}$ ) was daily administered via the same route.

Results: Dandelion remarkably improved the liver histology as evidenced by histopathological scoring with hematoxylin-eosin staining. Masson staining and hydroxyproline content similarly showed that dandelion decreased collagen deposition. Both mRNA and protein levels of a-smooth muscle actin and collagens 1 and 3 have been decreased after dandelion treatment compared to CCL4 group. Dandelion also downregulated the mRNA expressions of inflammatory factors interleukin-IL-1 $\beta$, tumor necrosis factor- $\alpha$, remodeling growth factor- $\beta 1$, cyclooxygenase-2, and nuclear factor kappa-B and decreased the myeloperoxidase activity. Additionally, the effects of dandelion were associated with the decreased levels of the hepatic oxidative stress markers (malondialdehyde and P. carbonyl) and elevation of the activity of superoxide dismutase activity. Dandelion's effect to alleviate the fibrosis and inflammation induced by CCL4 treatment in the livers and was more pronounced than with silymarin. The total antioxidant study of dandelion extract revealed that dandelion has notable ferric reducing antioxidant power and high total phenolic content.

Conclusion: Finally, these results suggest that dandelion prevents the progression of hepatic fibrosis induced by CCL4. The dandelion's antifibrotic effects could be attributed to its ability to scavenge free radicals and to attenuate inflammatory cells activations.

Keywords: Dandelion, Hepatic fibrosis, Protection, Oxidative stress, Hepatic stellate cell

\section{Background}

Liver fibrosis occurs as a compensatory response to the process of tissue repair in a wide range of chronic liver injures and inflammations (Cordero-Espinoza \& Huch, 2018). Chronic liver injuries and inflammations have been

\footnotetext{
*Correspondence: alaa17mm@gmail.com; a.amin@uaeu.ac.ae 'Hormone Evaluation Department, National Organization for Drug Control and Research (NODCAR), 6 Abu Hazem St., Pyramids, Giza, Egypt ${ }^{2}$ Biology Department, College of Science, United Arab Emirates University, Al-Ain, UAE

Full list of author information is available at the end of the article
}

implicated in the pathogenesis of a number of liver diseases including chronic viral and metabolic disorders. Dead or dying epithelial cells as well as phagocytes release inflammatory mediators that initiate inflammatory reaction (Higashi, Friedman, \& Hoshida, 2017). Among these mediators are transforming the growth factor beta 1 (TGF $\beta 1$ ), tumor necrosis factor (TNF $\alpha$ ), interleukin IL$1 \beta$, reactive oxygen species (ROS), and cyclooxygenase-2 (COX2) (Higashi et al., 2017; Park, Cha, Youn, Cho, \& Song, 2010; Wahid et al., 2018). The major driver of liver 
fibrogenesis is an activation of hepatic stellate cells (HSCs) which is the major cellular source of matrix proteinsecreting myofibroblasts (Higashi et al., 2017). Cellular changes accompanying HSC activation include morphological changes such as the appearance of the cytoskeletal protein $\alpha$-smooth muscle actin ( $\alpha$-SMA) and a dramatic increase in types I and III collagens (Friedman, 2008). This excess deposition of ECM disrupts the normal architecture of the liver that gradually degenerates the normal cellular function of the organ and causes liver failure with significant morbidity and mortality (Friedman, 2008).

Studies have demonstrated that liver fibrosis may be prevented and even reversed by bioactive food components and natural products including silymarin (Bae, Park, \& Lee, 2018). Natural product-based drugs recently have attracted extensive attention in the prevention and treatment of liver disease (Amin et al., 2016; Amin \& Mahmoud-Ghoneim, 2009; Amin \& Mahmoud-Ghoneim, 2011; Ashktorab et al., 2019; Hamza, 2010; Hamza et al., 2018; Li et al., 2018). Main reasons for the use of herbal drugs include their lower cost compared with conventional drugs, minor drug reactions hence reduced side effects and high safety (Bae et al., 2018). Among myriad of herbal drugs, silymarin, which is being explored for a wide variety of disorders such as oxidative stress, inflammatory disorders, and liver disorders (Ali et al., 2018), the usual therapeutic dose $200 \mathrm{mg} / \mathrm{kg}$ of silymarin administered to CCL4-induced model of liver fibrosis can inhibit the fibrogenic mechanism and the progression of initial liver fibrosis (Clichici et al., 2015; Neha, Jaggi, \& Singh, 2016)

Dandelion (Taraxacum officinale) is a member of the Asteraceae (Compositae) family and is a common perennial weed distributed in the warmer temperature zones of the Northern Hemisphere (Schutz, Carle, \& Schieber, 2006). As dandelion is an edible plant, it has been used as traditional herbal medicine in the Arabian zones for the treatment of liver and spleen ailments (Schutz et al., 2006). It has been used as folk medicines in China, India, Russia, Pakistan, and Italy for the treatment of chronic liver diseases (Devaraj, 2016; Martinez et al., 2015). Several health-promoting properties, including diuretic, anti-inflammatory, anti-carcinogenic, and anti-oxidative activities, have been attributed to the use different parts of dandelion (Devaraj, 2016; Martinez et al., 2015). Dandelion contains a wide array of phytochemicals whose biological activities are explored in various human health care areas (Devaraj, 2016; Martinez et al., 2015). These include sesquiterpene lactones, terpenoids, polysaccharides, and phenolic compounds (Gonzalez-Castejon, Visioli, \& Rodriguez-Casado, 2012; Schutz et al., 2006; Williams, Goldstone, \& Greenham, 1996). Recently, dandelion has garnered attention for its antioxidant and its anti-inflammatory effects and its possible beneficial effects against the development of obesity, cancer, and numerous cardiovascular risk factors (Jeon, Kim, \& Kim, 2017; Ovadje, Ammar, Guerrero, Arnason, \& Pandey, 2016; Rehman et al., 2017). Dandelion continues to be commercialized as herbal formulation mainly for its potential to prevent or ameliorate the outcome of several chronic liver disorder such liver fibrosis. Yet, it received very limited research attention. Few early studies reported dandelion's anti-inflammatory, anti-oxidative, and the hepatoprotective effects of acute liver damage induced in animals by different chemicals such as by galactosamine (Park, Kim, Purck, Noh, \& Song, 2007), carbon tetrachloride (Clichici et al., 2015; Park et al., 2010) and acetaminophen (Colle et al., 2012), and chronic CCL4 liver damage (Al-Malk, Abo-Golayel, Abo-Elnaga, \& Al-Beshri, 2013). Administration of dandelion root water-ethanoic extract for 10 days ameliorated the CCL4-induced hepatic fibrosis in mice (Domitrovic, Jakovac, Romic, Rahelic, \& Tadic, 2010). This study suggested that administration of dandelion root extract promotes the complete regression of fibrosis and the enchantment of hepatic regenerative capabilities. This investigation was designed to evaluate the protective effects of dandelion root extract on hepatic fibrosis in male rats induced by CCL4 and its relationship with oxidative stress, inflammation, and HSC activation.

\section{Materials and methods}

\section{Chemicals}

The herbal preparation of dandelion capsule was manufactured by Herbal Factors Company, Ltd. (SKU 4501, LOT778496, 1550 United Boulevard, Coqutlam, BC, Canada V3: 6Y2); each capsule contains $800 \mathrm{mg}$ of dandelion extracted roots of Taraxacum officinale. Chloramin $\mathrm{T}$, types I and III collagens, N-methyl-2phenylindol, Folin-Ciocalteu reagent, pyrogallol, superoxide dismutase, catalase, 2, 4-dinitophenylhydrazine, odianisidine, p-dimethyl-amino-benzaldehyde, and bovine albumin were obtained from Sigma Chemical Co. (St. Louis, MO). Rabbit monoclonal anti- $\alpha$-smooth muscle actin (SMA) (ab32575) antibody, rabbit polyclonal anticollagen 1 (ab21287), and 3 antibody (ab7778) were purchased from Abcam, and all other chemicals were obtained from local commercial suppliers.

\section{Animals}

Adult male albino rats (150-200 g) of the Wistar strain were obtained from the Animal House, National Organization for Drug Control and Research (NODCAR, Cairo, Egypt). They were maintained on standard pellet diet and tap water ad libitum and were kept in polycarbonate cages with wood chip bedding under $12 \mathrm{~h}$ light/ dark cycle and room temperature $22-24{ }^{\circ} \mathrm{C}$. Rats were acclimatized to the environment for 1 week prior to experimental use. 


\section{Induction of liver fibrosis}

Fibrosis was induced by an oral administration of $20 \%$ CCL4/corn oil, $1 \mathrm{ml} / \mathrm{kg}$ body weight, twice a week for 8 weeks to produce slowly reversible cirrhosis, as described by Varga, Brenner, and Phan (Varga, Brenner, \& Phan, 2005) and Hamza (Hamza, 2010).

\section{Determination of total phenolic content of dandelion}

Total phenolic content was determined by the method of Singleton (Singleton, Orthofer, \& Lamuela-Raventos, 1999) using the Folin-Ciocalteu reagent. Results were expressed in milligrams of gallic acid equivalent per grams dry weight of crude plant material.

\section{Determination of total antioxidant capacity of dandelion}

The total antioxidant capacity (TAC) in crude extract was evaluated using ferric reducing antioxidant power (FRAP) assay (Benzie \& Strain, 1996). The FRAP assay measures the change in absorbance at $593 \mathrm{~nm}$ due to the formation of a blue colored ferrous-tripyridyltriazine complex from colorless oxidized ferric form by the action of electron donating antioxidants. Ascorbic acid was used as a standard for the calibration curve.

\section{Treatment regime}

Twenty-four rats were randomly divided into four groups (six rats each) and were subjected to the following treatments; the first group (fibrotic group) has received an oral administration of $20 \%$ CCL4/corn oil, 1 $\mathrm{ml} / \mathrm{kg}$ body weight, twice a week for 8 weeks to produce a slow reversible cirrhosis; the second group (control group) has received corn oil ( $1 \mathrm{ml} / \mathrm{kg}$ body weight); the third group (protected groups) and the fourth group (standard group) have received CCL4. Following the administration of CCL4, dandelion $500 \mathrm{mg} / \mathrm{kg}$ body weight and silymarin $200 \mathrm{mg} / \mathrm{kg}$ body weight were administrated orally and continued daily for 8 weeks. Powder from dandelion root capsule was suspended in $10 \mathrm{ml}$ of distilled water before administration. Doses of dandelion and silymarin were selected based on their previously reported hepatoprotective properties (Park et al., 2010). The time intervals between the administration of CCL4 and each of Dandelion and silymarin were $5 \mathrm{~h}$ to avoid the disturbance of the absorption of each agent. The normal control group was treated daily with an equivalent volume of water for 8 weeks. After 8th week, all rats were anesthetized with $3 \%$ sodium pentobarbital $(45 \mathrm{mg}$ / $\mathrm{kg}$, i.p.), and blood samples were collected from the retro-orbital plexus. After the blood was drown from rats, the animals were euthanized by cervical dislocation under 3\% sodium pentobarbital anesthesia, and the liver was quickly taken out and weighted after washed with cold normal saline.

\section{Sample preparation}

The livers from all animals were collected and weighed; then, harvested liver tissues were fixed in $10 \%$ buffered formalin, for histopathological examination. Other liver tissues were removed and rinsed with ice-cold isotonic saline, quickly frozen in liquid nitrogen, and stored at $80{ }^{\circ} \mathrm{C}$ for analysis of fibrotic, oxidative stress, and inflammatory markers. The serum was collected by centrifuging the blood samples in a refrigerated centrifuge $\left(4{ }^{\circ} \mathrm{C}\right)$ at $3000 \mathrm{rpm}$ for $20 \mathrm{~min}$ (A. A. (Hamza, 2010)) and stored at $4{ }^{\circ} \mathrm{C}$. For biochemical determination, frozen liver samples were homogenized in ice-cold Tris-HCL buffer (150 mM, pH 7.4). The wt/vol ratio of the tissue to the homogenization buffer was 1:10 wt/vol.

\section{Biochemical assays and histopathology}

The level of malondialdehyde (MDA), as marker of lipid peroxidation, was measured according to the method of Gerard-Monnier (Gérard-Monnier et al., 1998), where MDA reacts with $\mathrm{N}$-methyl-2-phenylindol and forms a blue complex with absorption maximum at $586 \mathrm{~nm}$. Two hundred microliter of liver sample was added to $650 \mu \mathrm{l}$ of a solution containing $10 \mathrm{mM} \mathrm{N}$-methyl-2-phenylindol in a mixture of acetonitrile/methanol (3:1), followed by adding $150 \mu \mathrm{l}$ of $37 \% \mathrm{HCl}$. After $1 \mathrm{~h}$ of incubation at $45{ }^{\circ} \mathrm{C}$, the absorbance was measured at 586 $\mathrm{nm}$. The MDA concentration was determined against MDA standard curve. The results were expressed as nanomole of MDA per milligram of protein.

The level of liver superoxide dismutase (SOD) enzyme was assayed according to the method described by Nandi and Chatterjee (Nandi \& Chatterjee, 1988). It is based on the ability of SOD to inhibit the auto-oxidation of pyrogallol at alkaline $\mathrm{pH}$. Two $2 \mathrm{ml}$ of reaction mixture contained $1 \mathrm{mM}$ diethylene triaminepenta acetic acid, $40 \mu \mathrm{l}$ catalase, $50 \mathrm{mM}$ Tris-cacodylate buffer, $\mathrm{pH}$ 8.5 mixed with $15 \mu$ of liver homogenate. The reaction was started by the addition of $200 \mu \mathrm{l}$ of freshly prepared $2.6 \mathrm{nM}$ of pyrogallol solution in $10 \mathrm{mM} \mathrm{HCl}$. Change in absorbance was recorded at $420 \mathrm{~nm}$ for $5 \mathrm{~min}$ at 1-min interval. One unit of SOD has been described to cause $50 \%$ inhibition of auto-oxidation pyrogallol present in the assay mixture.

Hepatic protein carbonyl (P. carbonyl) contents were determined based on the method of Reznick and Packer (Reznick \& Packer, 1994). This method is based on spectrophotometric detection of the reaction of 2, 4dinitophenylhydrazine with $\mathrm{P}$. carbonyl to form protein hydrazones at $370 \mathrm{~nm}$. The results were expressed as nanomole of carbonyl group per milligram of protein with molar extinction coefficient of 22,000 M/cm. Myeloperoxidase (MPO) activity in hepatic homogenate was assayed based on the method of Hillegass (Hillegass, Griswold, Brickson, \& Albrightson-Winslow, 1990). 2.95 
$\mathrm{ml}$ of substrate contained $50 \mathrm{mM}$ potassium phosphate buffer containing $0.53 \mathrm{mM}$ o-dianisidine and $20 \mathrm{mM}$ $\mathrm{H}_{2} \mathrm{O}_{2}$ mixed with $50 \mu \mathrm{l}$ of liver homogenate. Change in absorbance was recorded at $460 \mathrm{~nm}$ for $5 \mathrm{~min}$ at 1 -min interval. One unit of MPO was defined as amount of MPO present that degrades $1 \mu \mathrm{M}$ peroxide per a minute at $25{ }^{\circ} \mathrm{C}$.

Liver collagen concentrations were performed by measuring hydroxyproline (HP) content in liver samples using a modification of the method of Edwards and Brien (Edwards \& Brien, 1980). Briefly, $0.5 \mathrm{ml}$ of $20 \%$ liver homogenate was digested in $1 \mathrm{ml}$ of $6 \mathrm{~N} \mathrm{HCl}$ at 110 ${ }^{\circ} \mathrm{C}$ for $18 \mathrm{~h}$ then was dried at $60{ }^{\circ} \mathrm{C}$ under vacuum. The sediment was dissolved in $400 \mu \mathrm{l}$ of acetate buffer $\mathrm{pH}$ 6.5; then, $0.8 \mathrm{ml}$ of $1.41 \%$ chloramin $\mathrm{T}$ reagent dissolved in acetate buffer $\mathrm{pH} 6.5$ was added. After incubation for $25 \mathrm{~min}$ at room temperature, $0.8 \mathrm{ml}$ of mixture containing $15 \mathrm{~g}$ p-dimethyl-amino-benzaldehyde and $30 \%$ perchloric acid in $60 \mathrm{ml} \mathrm{n}$-propanol was added, and mixture was incubated at $60{ }^{\circ} \mathrm{C}$ for $25 \mathrm{~min}$. After cooling, the absorbance of samples and standards was measured at 550 $\mathrm{nm}$. The results were expressed as microgram of HP per milligram of protein. The total protein content of liver was performed according to the Lowry method as modified by Peterson (Peterson, 1977). Aspartate aminotransferase (AST) and alanine aminotransferase (ALT) activities as well as albumin and total protein concentrations were estimated in serum using Randox reagent kits (Randox Laboratories Ltd., Co. Antrim, UK) and following their instruction manual. In all the estimations, absorbance was recorded using a PerkinElmer, Lambda 25 UV/VIS spectrophotometer.

\section{Histopathological evaluation}

Pieces of the livers were fixed in $10 \%$ neutral phosphatebuffered formalin and embedded in paraffin before cutting into $5-\mu \mathrm{m}$ sections. The hydrated tissue sections were stained with hematoxylin and eosin ( $\mathrm{H} \& \mathrm{E})$ and Masson-Trichrome, for the different histological examinations. The sections were examined under an Olympus DX41-light microscope (Honduras St., London, UK). In hematoxylin and eosin stain, the presence of necrosis, inflammation, and necrosis was evaluated and graded as follows: grade 0 , absent; grade 1 , present in one third of the lobules; grade 2, present in two thirds of the lobules; and grade 3, present in all of the lobules. In Masson stain of collagen, fibrosis was graded according to the method of Gui, Wei, Wang, Wu, Sun, and Chen (Gui et al., 2006): grade 0, normal (no visible fibrosis); grade 1 , fibrosis present (collagen fiber present as small septa in portal area, central area, or peripheral area); grade2, mild fibrosis (collagen fiber extended as septa from portal tract to central vein forming incomplete septa); grade 3, moderate fibrosis (collagen fibers formed thin complete septa); and grade 4, severe fibrosis (collagen fibers formed thick septa and pseudo lobe formation).

\section{Immunohistochemical evaluation}

Liver tissue sections were mounted onto slides, dewaxed in xylene, and hydrated and subjected to heat-induced antigen retrieval according to standard protocols. The levels of $\alpha$-smooth muscle actin ( $\alpha$-SMA) and types I and III collagens were determined by immunohistochemically methods according to the protocols described by Varga et al. (Varga et al., 2005). The numbers of $\alpha$ SMA and types I and III collagen positive cells were counted in five randomly selected high-power fields $(x$ 400) per liver section for six animals of each group.

\section{Real-time quantitative reverse-transcriptase polymerase chain reaction (RT-PCR) analysis}

Total RNA was isolated from liver frozen tissue by a RNeasy Mini Kit (QIAGEN, Valencia, CA) and assessed with a dual spectrophotometer Gene JET Kit (Thermo Fisher Scientific Inc., Germany, \#K0732). RT-PCR was used for quantitative analysis of gene expression of TNF- $\alpha$, NF-kB, IL- $1 \beta$, COX2 TGF- $\beta, \alpha$-SMA, Colla1, and Colla 3 . The PCR reaction was carried out in 48well plate Step One real-time PCR systems (Applied Biosystems, Foster city, USA), and results were analyzed using the Applied Biosystems software version 2. Twenty nanograms of purified RNA from each sample was applied for reverse transcription with subsequent quantitative PCR amplification with Bioline, amedian lifescience Company, UK (SensiFASTTMSYBR ${ }^{\circ} \mathrm{Hi}$-ROX) One-step Kit (Catalog number PI-50217V). Thermal profile was as follows: $45^{\circ} \mathrm{C}$ for $20 \mathrm{~min}$ in one cycle (for cDNA synthesis) followed by $10 \mathrm{~min}$ at $95{ }^{\circ} \mathrm{C}$ for reverse transcriptase enzyme inactivation. Forty cycles of PCR amplification were further carried out as follows: $10 \mathrm{~s}$ at $95{ }^{\circ} \mathrm{C}, 30 \mathrm{~s}$ at $58{ }^{\circ} \mathrm{C}$, and $1 \mathrm{~min}$ at $72{ }^{\circ} \mathrm{C}$. Changes in the expression of each target gene were normalized relative to the mean cycle threshold (CT) values of the housekeeping gene glyceraldehyde 3-phosphate dehydrogenase (GAPDH) by $\Delta \mathrm{Ct}$ method. The sequence of primers for all studied genes was shown in Table 1 .

\section{Statistical analysis}

Data were expressed as mean \pm SEM. Comparisons among multiply groups were performed by one-way analysis of variance (ANOVA) followed by Dunnett's $t$ test post-hoc analysis test for multiple comparisons with $P<0.05$ being considered as statistically significant. In a nonparametric analysis, differences between the groups were performed by the Kruskal-Wallis $H$ test, and the significant of the differences between the groups was determined by MannWhitney $U$ test. All statistical analysis was performed by SPSS (version 20) statistical program (SPSS Inc., Chicago, 
Table 1 The gene-specific primers used for RT-PCR

\begin{tabular}{|c|c|c|}
\hline $\begin{array}{l}\text { Gene } \\
\text { name }\end{array}$ & Primer sequence $5^{\prime}-3^{\prime}$ & $\begin{array}{l}\text { Gene bank accession } \\
\text { number }\end{array}$ \\
\hline$\overline{T N F-a}$ & $\begin{array}{l}\text { F: AACTCGAGTGACAAGCCCGTAG } \\
\text { R: GTACCACCAGTTGGTTGTCTTTGA }\end{array}$ & NM_012675.3 \\
\hline NF-kB & $\begin{array}{l}\text { F: CATTGAGGTGTATTTCACGG } \\
\text { R: GAACACAATGGCCACTTGCC }\end{array}$ & NM_199267.2 \\
\hline$I L-1 \beta$ & $\begin{array}{l}\text { F: GCTGTGGCAGCTACCTATGTCTTG } \\
\text { R: AGGTCGTCATCATCCCACGAG }\end{array}$ & NM_031512.2 \\
\hline $\operatorname{cox}-2$ & $\begin{array}{l}\text { F: ACTTGCTCACTTTGTTTCATTC } \\
\text { R: TTTGATTAGTACTGTAGGGTTAATG }\end{array}$ & S67722.1 \\
\hline TGF- $\beta$ & $\begin{array}{l}\text { F: TGCGCCTGCAGAGATTCAAG } \\
\text { R: AGGTAACGCCAGGAATTGTTGCTA }\end{array}$ & NM_021578.2 \\
\hline a-SMA & $\begin{array}{l}\text { F: ACCAACTGGGACGACATGGAG } \\
\text { R: CGTGAGGATCTTCATGAGGTAGTC }\end{array}$ & NM_031004.2 \\
\hline Colla1 & $\begin{array}{l}\text { F: GAACTTGGGGCAAGACAGTCA } \\
\text { R: GTCACGTTCAGTTGGTCAA }\end{array}$ & NM_053304.1 \\
\hline Colla3 & $\begin{array}{l}\text { F: TTGATGTGCAGCTGGCATTC } \\
\text { R: GCCACTGGCCTGATCCATAT }\end{array}$ & NM_009930 \\
\hline GAPDH & $\begin{array}{l}\text { F: CCCCTTCATTGACCTCAACTAC } \\
\text { ATGG } \\
\text { R: GCCTGCTTCACCACCTTCTTGA } \\
\text { TGTC }\end{array}$ & NM_017008.4 \\
\hline
\end{tabular}

IL, USA). Figures were done using GraphPad Prism program (version 5) (San Diego, California, USA).

\section{Results}

\section{Dandelion's overall antioxidant and phenolic contents}

The antioxidant and phenolic overall contents are presented in Fig. 1. The FRAP assay is a direct test of total antioxidant capacity (TAC). In the present study, dandelion had high FRAP value. TAC of dandelion was concentration dependent where a concentration of $1000 \mathrm{mg}$ of dry herb contained the highest TAC which equals to $21.45 \mu \mathrm{mol}$ ascorbic acid equivalent. Dandelion was found to contain high total polyphenolic content and equals to $6.88 \mathrm{mg}$ gallic acid equivalent per $1000 \mathrm{mg}$ of dry dandelion.

\section{Dandelion improved liver function in CCL4-treated rats}

Figure 2 shows the effects of dandelion on liver function's biomarkers of in rats treated with CCL4. In rats treated with CCL4, activities of AST and ALT were significantly increased in serum whereas serum levels of albumin and total proteins were significantly decreased compared to normal control group. In contrast, both serum AST and ALT activities were significantly decreased while serum levels of albumin and protein were significantly increased in the dandelion treatment group. These effects were comparable to that of the well-known hepatoprotective agent silymarin. The hepatoprotective effects of dandelion were superior to that of silymarin.

\section{Dandelion attenuated liver damage and fibrosis in CCL4- treated rats}

To further evaluate the effect of dandelion on liver damage and fibrosis, $\mathrm{H} \& \mathrm{E}$ and Masson's trichromic stained sections were performed (Fig. 3). CCL4 treatment induced severe liver damage, which included marked fatty degeneration, necrosis of hepatocytes, and massive intrusion of inflammatory cells to the liver of CCL4-treated group (Fig. 3a, b). Normal lobular architecture was observed in the control group. However, concomitant treatment of dandelion significantly reduced histological scores of fatty

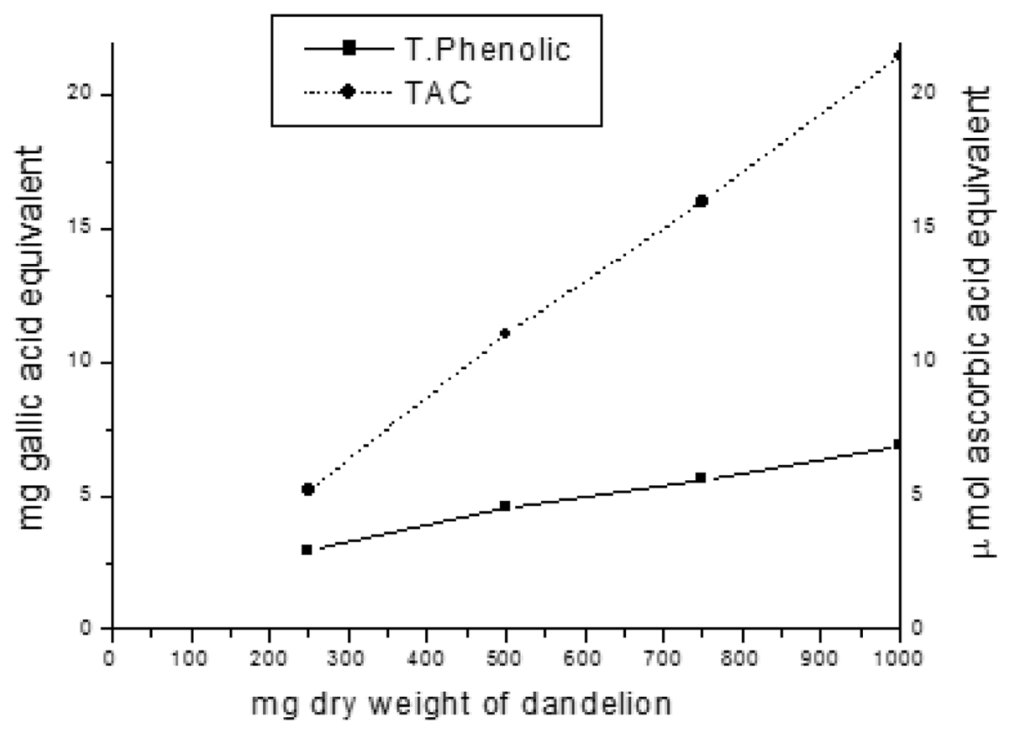

Fig. 1 Total phenolic and total antioxidant contents of dandelion 
A

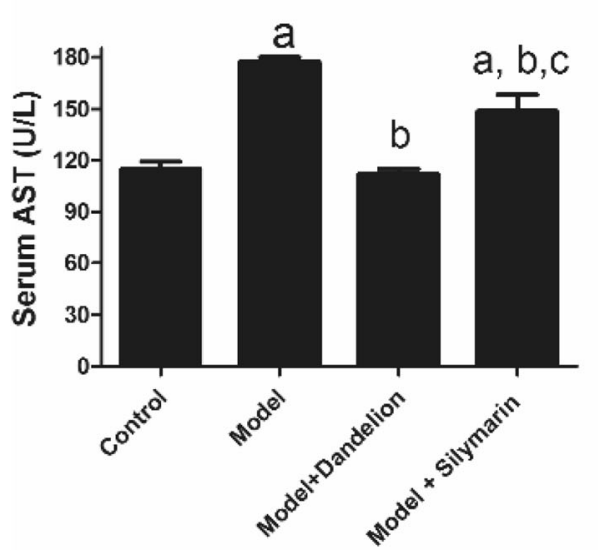

C

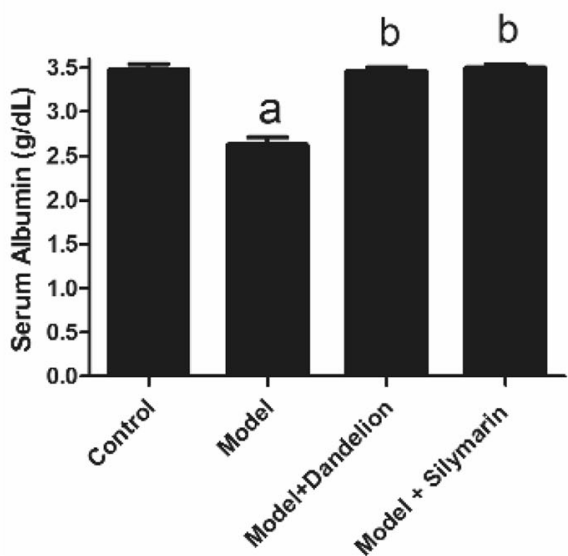

B

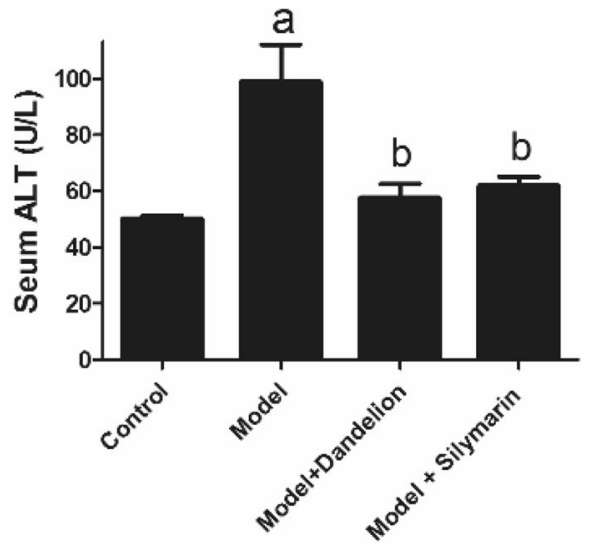

D

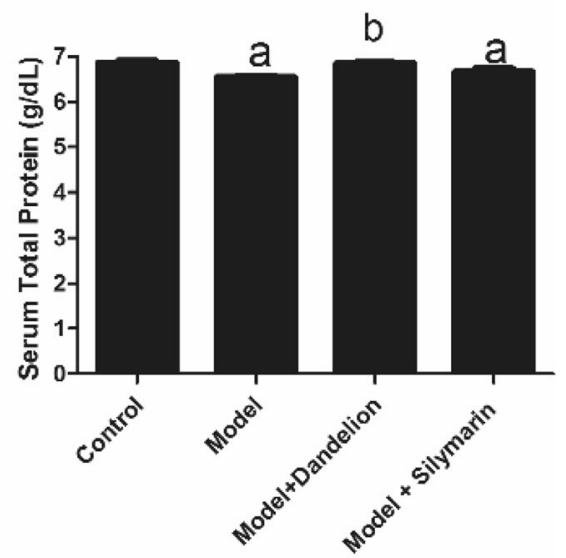

Fig. 2 Effect of dandelion and silymarin on serum markers of liver function in CCL4-treated (model). Data are expressed as mean \pm SEM for six animals in each group. Units of ALT and AST are IU/L; units of albumin and T. protein are g/dl. a $P<0.05$ vs. control group. $\mathbf{b} P<0.05$ vs. model group

degeneration, necrosis, and inflammation in comparison with CCL4-treated group. Silymarin treatment markedly lessened the degrees of liver necrosis and inflammatory cell intrusions, but the efficacy of dandelion in restoring normal architecture of the liver is more evident. Level of hepatic fibrosis was examined with Masson stain and HP content as shown in Fig. $3 \mathrm{c}-\mathrm{e}$. First, liver sections were stained by Masson stain, which stains collagen fibers blue. After treatment with CCL4, obvious increase in fibrosis was noted in CCL4-treated group compared with control group. Treatment with dandelion and silymarin barely showed signs of liver fibrosis (Fig. 3d). Interestingly, the level of liver fibrosis and size of fibrous septa were obviously less in dandelion- and silymarintreated groups. Finally, analysis of hepatic HP content, the major component of collagen protein, was carried out as a liver fibrosis biomarker (Fig. 3e). In agreement with the results of Masson stain, HP content was significantly higher in the liver of CCL4-treated group and further alleviated by the treatment with either dandelion or silymarin.

\section{Effect of dandelion on hepatic oxidative stress markers in CCL4-treated rats}

To investigate the effect of dandelion and silymarin on liver's oxidative stress caused by CCL4, hepatic MDA and P. carbonyl contents as well as SOD activity were detected. Figure 4 shows the effects of dandelion and silymarin on CCL4-induced oxidative stress damage in rats. CCL4 treatment caused a significant increase in hepatic content of MDA and P. carbonyl and a significant decrease in hepatic SOD activity compared with control group. Administration of each of dandelion and silymarin, normalized hepatic contents of MDA and P. carbonyl with partly prevented the decrease of SOD's activity. Compared with dandelion group, there was a significant improvement in oxidative stress in silymarin- 


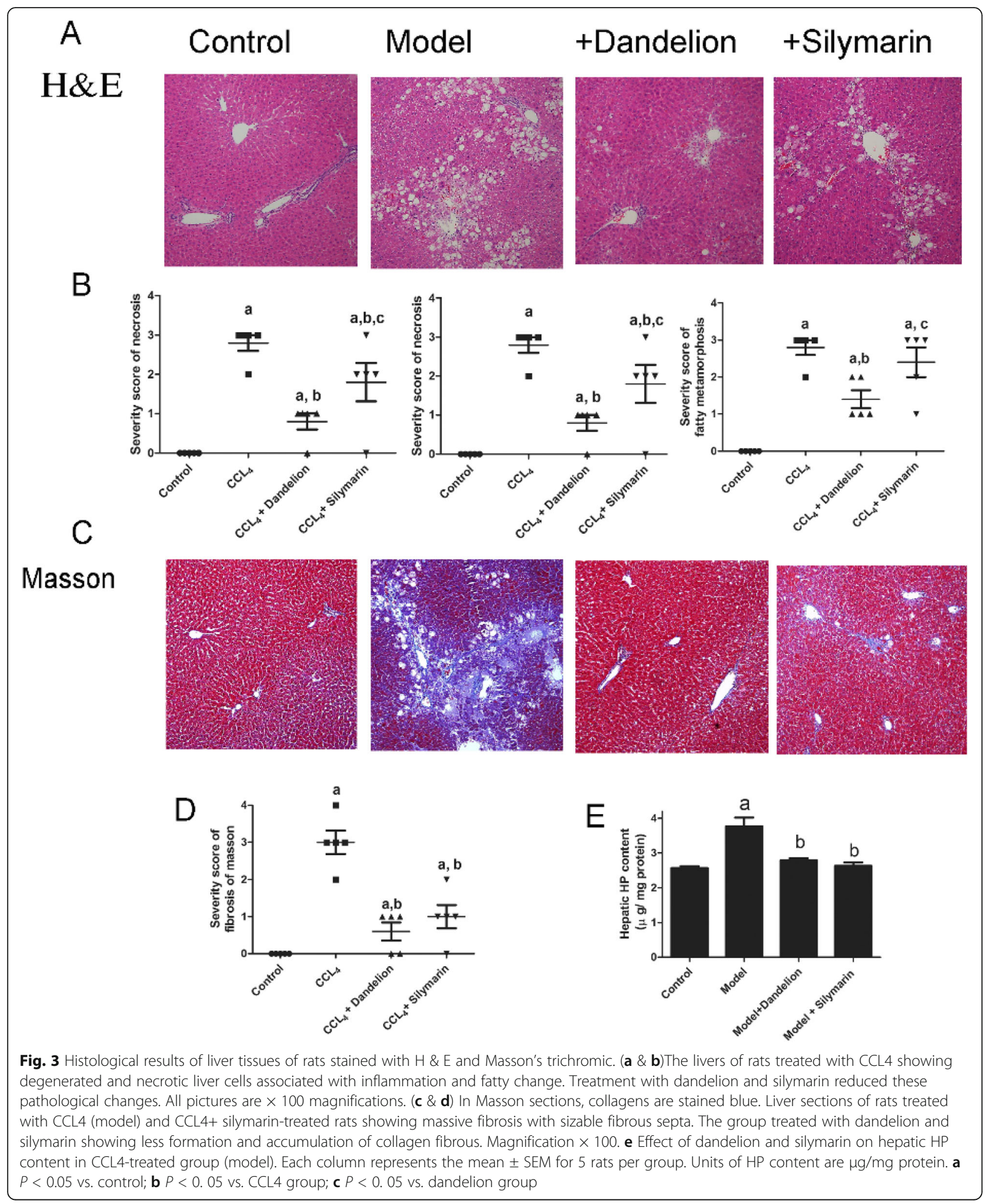



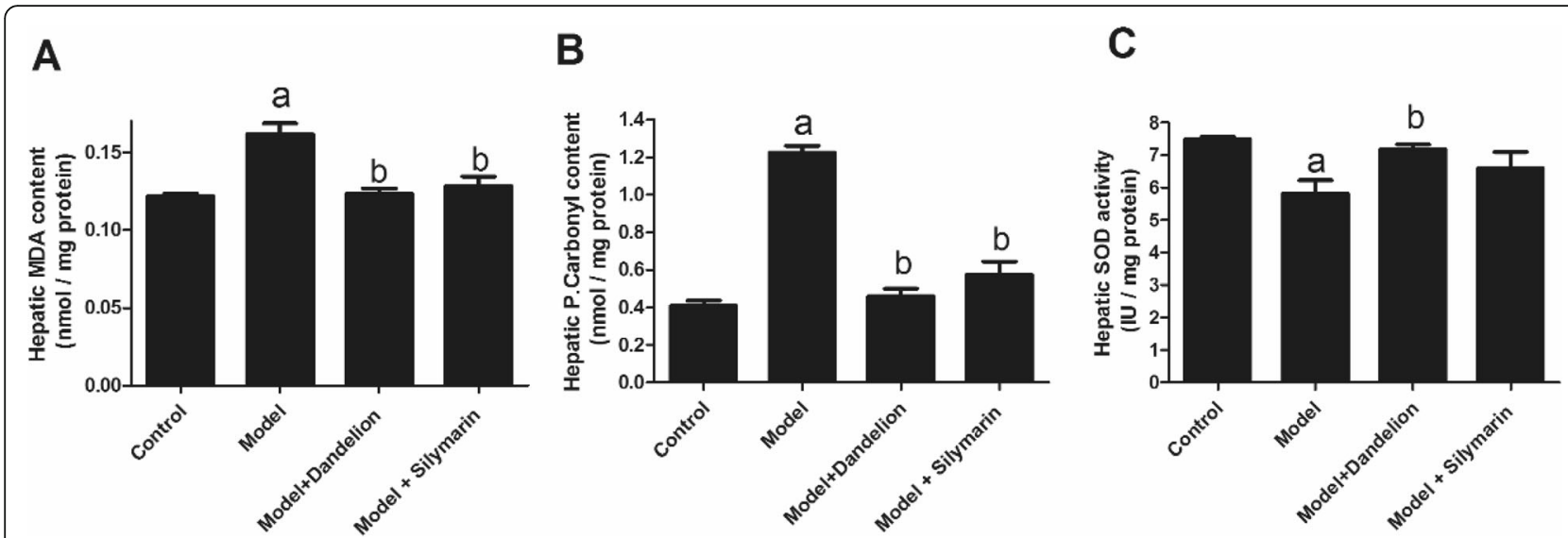

Fig. 4 Effect of dandelion and silymarin on hepatic markers of oxidative stress in CCL4 treated groups (model). Data are presented as mean \pm SEM for 6 animals per group. MDA and P. carbonyl units are nmol/mg protein; SOD enzyme unit is IU/mg protein. a $P<0.05 \mathrm{vs}$. control group. $\mathbf{b}$ $P<0.05$ vs. model group

treated group, but dandelion revealed the best efficacy in normalization of hepatic SOD activity and P. carbonyl content.

\section{Effects of dandelion on expression of a-SMA and collagen types 1 and 3 in CCL4-treated rats}

We confirmed stellate cell activation during fibrosis in liver sections by identifying the expression of the $\alpha$-SMA which is a good marker of stellate cell activation during fibrosis. The expression of $\alpha$-SMA marker in immunostaining sections was evident mostly in the blood vessel wall of the normal group. As expected, the number of $\alpha$ SMA positive cells was significantly increased in fibrous septa and areas of inflammations in CCL4-treated group (Fig. 5a). This effect was confirmed by mRNA expression levels of $\alpha$-SMA (Fig. 5c) which showed their upregulation of the livers of fibrotic group. Treatment with either dandelion or silymarin has significantly attenuated the number of $\alpha$-SMA positive cells compared to the fibrotic group. Similarly, dandelion and silymarin significantly decreased the mRNA expression levels of $\alpha$-SMA in rats compared to those of the CCL4-treated group (Fig. 5c). Dandelion revealed the best effects in mRNA expression of this marker compared to silymarin-treated group. Collagen types I and III were immunohistochemically labeled and were stained brown. Collagen was weakly deposited around centrolobular veins of the normal group. CCL4 group displayed the depositions of collagen types I and III, forming fibrous septa surrounding the lobules (Fig. 5a, b). Treatment with dandelion and silymarin attenuated collagen accumulation and the number of collagen types I and III positive cells in CCL4-treated rats. In addition, excessive deposition of ECM in the fibrotic liver was confirmed by real-time PCR (Fig. 5c), and the amount of collagen 1 and collagen 3 mRNA was significantly higher in CCL4-treated rats than in control rats; however, dandelion treatment markedly alleviated the effect of CCL4 and reduced the expression of collagen 1 and collagen $3 \mathrm{mRNA}$ (Fig. 5c). Treatment with dandelion showing the best effects in those markers of liver fibrosis was compared to silymarin-treated group.

\section{Effects of dandelion on expression of inflammatory markers in CCL4-treated rats}

The hepatic MPO activity and mRNA levels of inflammatory markers, including IL-1 $\beta$, TNF- $\alpha$, TGF $\beta$, NF-kB, and COX-2, in rat livers are shown in Fig. 6. MPO activity of the liver was adopted as a marker of oxidative stress and inflammation and tissue neutrophil accumulation and activation. Hepatic MPO activity was significantly elevated in CCL4-intoxicated group in comparison with control group. Dandelion and silymarin treatment significantly decreased hepatic MPO activity compared to CCL4-treated group (Fig. 6). CCL4 significantly upregulated the mRNA levels of IL-1 $\beta$, TNF- $\alpha$, TGF $\beta, N F-k B$, and COX-2 in the livers of rats compared to control group. Dandelion and silymarin significantly decreased the mRNA expression level of mRNA of IL- $1 \beta$, TNF- $\alpha$, TGF $\beta$, NF-kB, and COX-2 in the livers of rats compared to CCL4-treated group (Fig. 6). Dandelion revealed the best effects in inhibition of inflammatory response of livers compared to silymarin-treated group.

\section{Discussion}

The current study showed that dandelion treatment reduced liver injury, improved liver function, and decreased ECM deposition. These protecting consequences can be attributed, at least in part, to the reduction of HSC activation, the inhibition of inflammatory signaling pathway, and the suppression of oxidative stress-induced damage. Present results showed that repeated doses of 


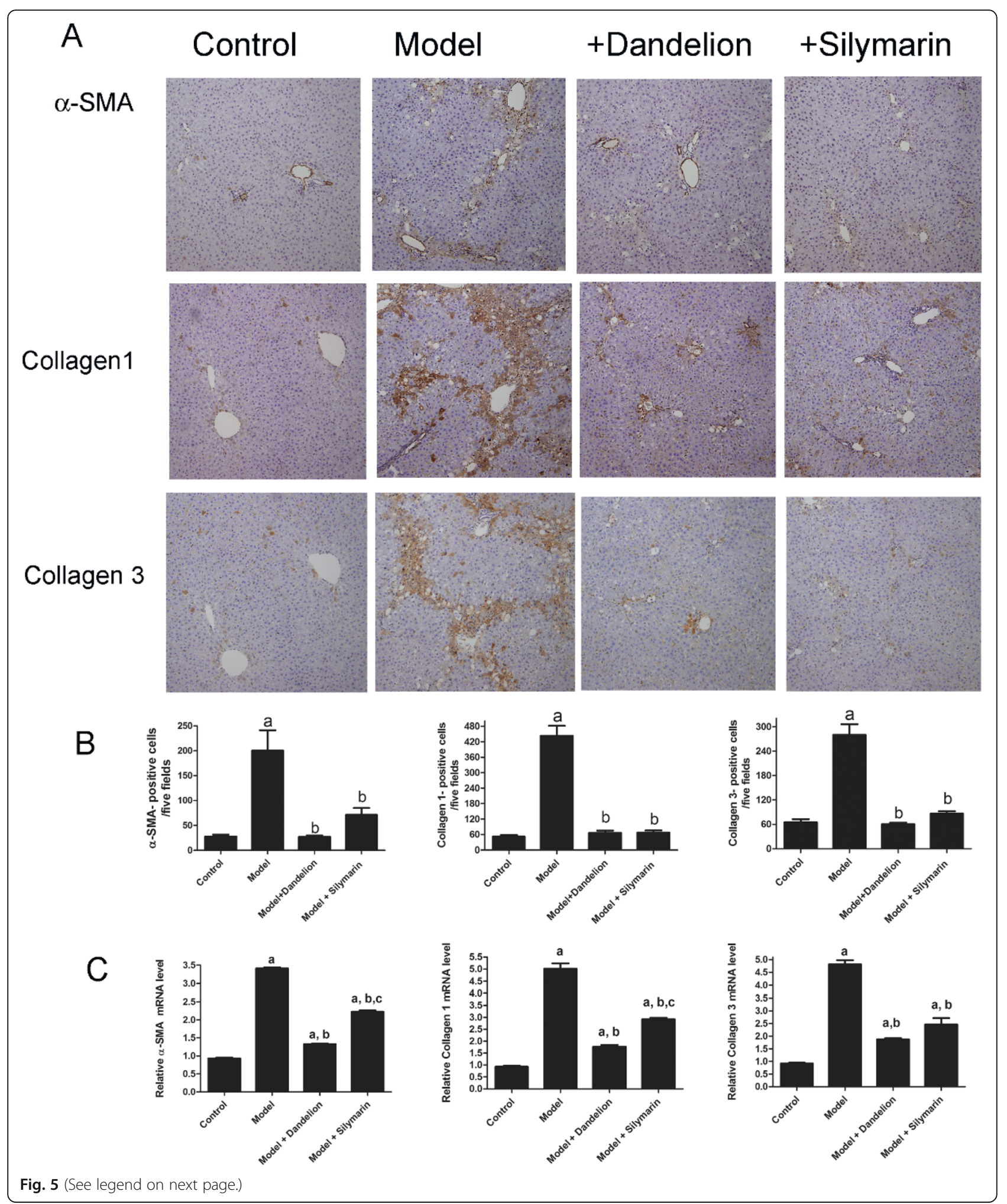


(See figure on previous page.)

Fig. 5 The expression of a-SMA collagens I and III positive cells of liver tissues of rats was determined by immunohistochemical satin (a and $\mathbf{b}$ ) and by mRNA expression in the liver by quantitative RT-PCR (c). Representative histological pictures (a) and the semi-quantitative analysis (b) showing the expression of a-SMA and collagens I and III positive cells in different experimental groups. All pictures are $\times 100$ magnifications. In control section, immunohistochemical staining is only revealed in vascular structures. In CCL4 sections, clear staining for a-SMA and collagens I and III is manifested along with the fibrous septa. The immunohistochemical expression of cells in each section was calculated by counting numbers of brown staining, $a$-SMA positive cells, in five fields per section at $\times 400$ magnification. $\mathbf{b}$ Columns represent the means \pm SEM for 6 animals per group. a $P<0.05$ vs. control group; $\mathbf{b} P<0.05$ vs. CCL4 group. Analysis of $\mathbf{a}-\mathrm{SMA}$ and types 1 and 3 collagen mRNA expression in the liver by quantitative RT-PCR ( $n=3$ per group). Data were normalized to GAPDH mRNA. Data are presented as means \pm SEM. a $P<0.05$ vs. control group; $\mathbf{b} P<0.05$ vs. CCL4 group; $\mathbf{c} P<0.05$ vs. dandelion group

CCL4 caused a significant elevation in serum AST and ALT activities and a significant depletion of in serum albumin and total protein levels, indicating the injury of liver cells and the decrease in liver synthetic function. However, both dandelion and silymarin treatment attenuated serum AST and ALT activities indicating hepatoprotective effects against hepatocellular injury. In additions, dandelion treatment improved liver synthetic function confirmed by normalized serum albumin and total protein levels. Additionally, these hepatoprotective properties of dandelion were associated with improvements of liver histopathological changes. The present results are coincided with previous studies that showed the hepatoprotective effects of dandelion against hepatotoxicity induced by several chemicals (Colle et al., 2012; Park et al., 2010). Furthermore, hepatotoxicity of CCL4 model in the present work was accompanied with inflammation and fibrosis. Fibrogenesis is known to be associated with the necrosis and inflammation of the liver (Fortea et al., 2018; Wahid et al., 2018). CCL4 is considered one of the most used hepatotoxins in the experimental study of liver diseases. Hepatic responses in rats to chronic CCL4 administration are shown to be superficially like human cirrhosis (Varga et al., 2005). In the liver, CCL4 generates methyl trichloride radicals ( $\mathrm{CCl} 3 \cdot)$, which lead to pronounced centrilobular liver necrosis, induction of the inflammatory response, activation of HSCs, and increasing of extracellular matrix production (Ni et al., 2018; Wahid et al., 2018).

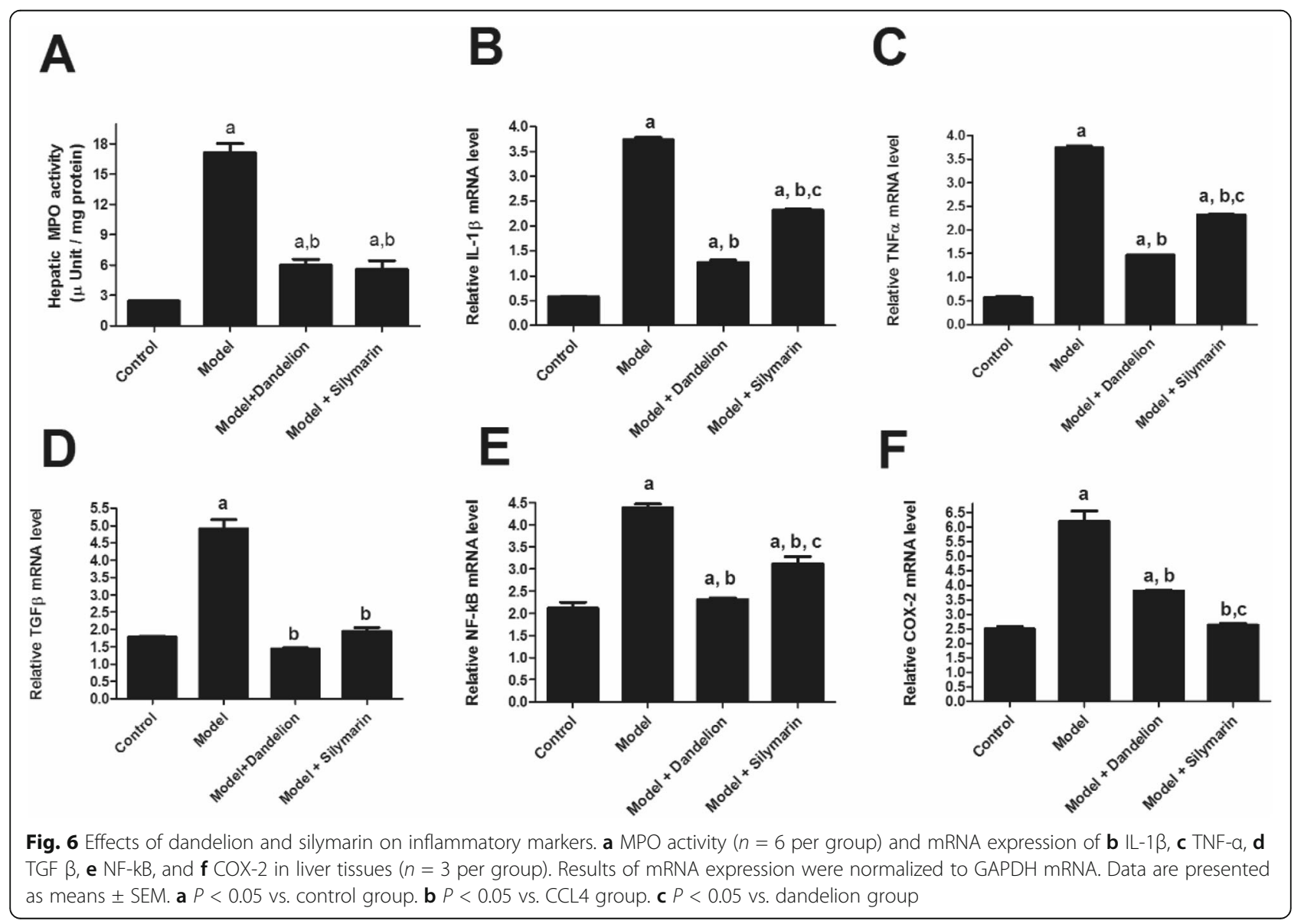


Excess deposition of ECM is the characteristic futures of liver fibrosis (Cordero-Espinoza \& Huch, 2018). Our results showed that CCL4 administration led to sever accumulation of collagen in the liver tissues as indicated from the result of the Masson staining, collagens 1 and 2 staining, and the increased level of HP, a considerable amino acid present in collagen. This was concomitant with the increased hepatic mRNA expression of collagen 1 and collagen 3 . Herein, the treatment with dandelion has a notable preventive effect against CCL4-induced liver fibrosis in rats. Besides, its improvement effect in the histological findings of Masson stain and HP content, dandelion markedly decreased the expressions of types 1 and 3 collagens. These findings point out that dandelion could inhibit the synthesis and deposition of collagen in liver tissue which may additionally be the pharmacological basis of its hepatoprotective property. Moreover, the results of this work confirmed that dandelion inhibited liver damage and fibrosis more effectively than silymarin.

Activation of HSCs is a core cellular event responsible for the production of collagen and the progression of liver fibrosis (Ni et al., 2018; Shay \& Hamilton, 2018). In CCL4-treated group of the present work, accumulation of hepatic fibers is associated with increased $\alpha$-SMA deposition indicates that activated HSCs are the primary source for the fibrosis seen in the CCL4-treated rats. This study showed that dandelion inhibited hepatic fibrosis and decreased protein and mRNA expression of $\alpha$-SMA; hence, dandelion might inhibit HSCs activation. Previous studies indicated that the protective effect of dandelion on liver fibrosis induced by CCL4 in mice was accompanied with the inactivation of HSCs (Domitrovic et al., 2010). Therefore, its antifibrotic effect may be due to the attenuation of HSCs activation.

The possible mechanism underling the hepatotoxic and fibrotic effect of CCL4 could be the generation of ROS by its metabolized into the highly reactive trichloromethyl radical (CCl3•) (Fortea et al., 2018; Ni et al., 2018). These radicals are assumed to initiate oxidative damage hepatocellular membrane via lipid peroxidation and protein oxidation and induced the release of inflammatory mediators from activated inflammatory cells (Fortea et al., 2018; Shay \& Hamilton, 2018). Furthermore, oxidative stress plays a vital role in the activation of HSCs during propagation of fibrogenesis (Higashi et al., 2017). The present study showed that repeated administration of CCL4 resulted in upregulation of oxidative stress markers MDA, levels of P. carbonyl, and depletion of SOD activity in liver dandelion administration, on the other hand, prevented the increase in MDA and P. carbonyl levels and ameliorated the depletion in SOD activity in liver. These findings suggest that the hepatoprotective antifibrotic effects of dandelion could be attributed to its antioxidant activity which coincides with the previous results (Dirleise (Colle et al., 2012; Davaatseren et al., 2013)). The antioxidant activity of dandelion was confirmed in this study by FRAP assay. Thus, the antioxidant property of dandelion could be attributed to its high phenolic contents that was confirmed in this study. These phenolic contents can act in several ways, including direct free radical scavenging, chelating of metal ions, and regeneration of membranebound antioxidants. This finding is consistent with previous findings that were demonstrated the polyphenolic compounds and antioxidant activity of dandelion root (Domitrovic et al., 2010) and leaf extracts (Davaatseren et al., 2013; Park et al., 2010). Dandelion was shown to prevent the toxicity of several other models via inhibiting oxidative damage (Park et al., 2010; Schutz et al., 2006). Several polyphenolic compounds were isolated from dandelion of fruits, leaves, flowers, and roots such as chicoric chlorogenic, caffeic, p-coumaric, ferulic, vanillic, and protocatechuic acids (Gonzalez-Castejon et al., 2012; Schutz et al., 2006).

Prolong hepatic damage triggers the progression of inflammatory responses and inflammatory cells infiltration including neutrophils and lymphocytes (Higashi et al., 2017). One of the important neutrophil specific enzymes released after neutrophil infiltrations is MPO (Hillegass et al., 1990). Our study showed increased hepatic MPO activity demonstrating that tissue injury, oxidative stress, and then fibrosis involve the contribution of neutrophil infiltrations. In the current work, elevation of inflammatory cell infiltrations and expressions of different inflammatory markers including IL-1 $\beta$, TNF- $\alpha$, TGF$\beta 1, C O X-2$, and NF- $\kappa B$ expression collectively with excess deposition of ECM revealed that the propagation of inflammation during repeated administration of CCL4 and chronic hepatic damage are strongly involved in activation of HSCs and promotion of fibrosis. The anti-inflammatory effect of dandelion was herein confirmed by the decrease in the MPO activity in the liver and by the inhibiting of the expressions of pro-inflammatory markers in liver tissues. We propose that the anti-inflammatory effect of dandelion could be involved in pharmacological mechanisms that lead to antifibrotic effect in the liver. A previous animal study has revealed the hepatoprotective effect of two polysaccharides isolated from dandelion, as shown by the alleviations of inflammatory responses and the amelioration of oxidative stress. These polysaccharides (administered at $304.92 \mathrm{mg} / \mathrm{kg}$ body weight, for 7 days) attenuated CCL4-induced hepatic damage in albino rats through the attenuated of inflammatory markers including NF-kB, iNOS, COX-2, TNF-a, and IL-1 (Gonzalez-Castejon et al., 2012; Park et al., 2010). 
Given its hepatoprotective and antifibrotic properties, silymarin is a commonly prescribed drug for patients with liver diseases (Clichici et al., 2015). In the present work, the hepatoprotective capacities of dandelion were shown to be more potent than our positive control, silymarin in inhibition of liver fibrosis and inflammation. This could attribute to the differences in polyphenolic compound classes and contents. Dandelion contains a wide array of phytochemicals including sesquiterpene lactones, terpenoids, polysaccharides, and phenolic compounds ((Gonzalez-Castejon et al., 2012; Martinez et al., 2015; Williams et al., 1996).

\section{Conclusion}

Dandelion was effective in the prevention of CCL4induced liver fibrosis in rats. The primary mechanism of this antifibrotic effect could be attributed to its antioxidant and anti-inflammatory properties.

\section{Abbreviations}

ALT: alanine aminotransferase; AST: Aspartate aminotransferase; CCL4: Carbon tetrachloride; COX2: Cyclooxygenase-2; FRAP: Ferric reducing antioxidant power; HP: Hydroxyproline; a-SMA: Smooth muscle a-actin; HSC: Hepatic stellate cells; TGF 1 1: Growth factor beta 1; ROS: Reactive oxygen species; TNF a: Tumor necrosis factor; SOD: Superoxide dismutase;

MDA: Malondialdehyde; P. carbonyl: Protein carbonyl; NF-Kb: Nuclear factor kappa-B

\section{Acknowledgements}

The authors would like to thank Hanan Mohamed Mehany and Mohamed Mustafa, at animal house, NODCAR, Egypt, for their excellent technical help.

\section{Authors' contributions}

A.A.H., F.M.L., M.G., and A.A. designed the study. A.A.H., F.M.L., M.G., and A.A. performed the experiments and did the statistical analysis. A.A.H., F.M.L., M.G. and A.A. assisted with methodology and contributed resources. A.A.H and A.A. wrote the first draft of the manuscript, and all authors contributed to the editing of the revised manuscript and approved the manuscript.

\section{Funding}

This work has been partially supported by grant Al Jalila Foundation fund \# 215098 for Amr Amin.

\section{Availability of data and materials}

The datasets supporting the conclusions of this article are available from the corresponding author on reasonable request.

\section{Ethics approval and consent to participate}

The protocol was conducted in accordance with standard guide to the care and use of experimental animals (Canadian Council of Animal Care 1993) and according to the ethical standards approved by the Animal Ethics Committee for animal care and use of NODCAR (NODCAR/II/45/19).

\section{Consent for publication}

Not applicable

\section{Competing interests}

The authors declared no potential conflicts of interest with respect to the research, authorship, and/or publication of this article.

\section{Author details}

${ }^{1}$ Hormone Evaluation Department, National Organization for Drug Control and Research (NODCAR), 6 Abu Hazem St., Pyramids, Giza, Egypt. ${ }^{2}$ Biology Department, College of Science, United Arab Emirates University, Al-Ain, UAE. ${ }^{3}$ The University of Chicago, Chicago, IL, USA.
Received: 25 March 2020 Accepted: 10 June 2020

Published online: 01 July 2020

\section{References}

Ali, M., Khan, T., Fatima, K., Ali, Q. U. A., Ovais, M., Khalil, A. T., et al. (2018). Selected hepatoprotective herbal medicines: Evidence from ethnomedicinal applications, animal models, and possible mechanism of actions. Phytotherapy Research, 32(2), 199-215.

Al-Malk, A. L., Abo-Golayel, M. K., Abo-Elnaga, G., \& Al-Beshri, H. (2013). Hepatoprotective effect of dandelion (Taraxacum officinale) against induced chronic liver cirrhosis. Journal of Medicinal Plants Research, 7(20), 1494-1505.

Amin, A., A Hamza, A., Daoud, S., Khazanehdari, K., Al Hrout, A., Baig, B., et al. (2016). Saffron-based crocin prevents early lesions of liver cancer: In vivo, in vitro and network analyses. Recent Patents on Anti-Cancer Drug Discovery, 11(1), 121-133.

Amin, A., \& Mahmoud-Ghoneim, D. (2009). Zizyphusspina-christi protects against carbon tetrachloride-induced liver fibrosis in rats. Food and Chemical Toxicology, 47(8), 2111-2119.

Amin, A., \& Mahmoud-Ghoneim, D. (2011). Texture analysis of liver fibrosis microscopic images: A study on the effect of biomarkers. Acta Biochimica et Biophysica Sinica, 43(3), 193-203.

Ashktorab, H., Soleimani, A., Singh, G., Amr, A., Tabtabaei, S., Latella, G., et al. (2019). Saffron: The golden spice with therapeutic properties on digestive diseases. Nutrients, 11(5), 943.

Bae, M., Park, Y. K., \& Lee, J. Y. (2018). Food components with antifibrotic activity and implications in prevention of liver disease. The Journal of Nutritional Biochemistry, 55, 1-11.

Benzie, I. F., \& Strain, J. J. (1996). The ferric reducing ability of plasma (FRAP) as a measure of (antioxidant power): The FRAP assay. Analytical Biochemistry, 293, $70-76$.

Clichici, S., Olteanu, D., Nagy, A. L., Oros, A., Filip, A., \& Mircea, P. A. (2015). Silymarin inhibits the progression of fibrosis in the early stages of liver injury in CCl(4)-treated rats. Journal of Medicinal Food, 18(3), 290-298.

Colle, D., Arantes, L. P., Gubert, P., da Luz, S. C. A., Athayde, M. L., Teixeira Rocha, J. B., et al. (2012). Antioxidant properties of Taraxacum officinale leaf extract are involved in the protective effect against hepatoxicity induced by acetaminophen in mice. Journal of Medicinal Food, 15(6), 549-556.

Cordero-Espinoza, L., \& Huch, M. (2018). The balancing act of the liver: Tissue regeneration versus fibrosis. The Journal of Clinical Investigation, 128(1), 85-96.

Davaatseren, M., Hur, H. J., Yang, H. J., Hwang, J. T., Park, J. H., Kim, H. J., et al. (2013). Taraxacum official (dandelion) leaf extract alleviates high-fat dietinduced nonalcoholic fatty liver. Food and Chemical Toxicology, 58, 30-36.

Devaraj, E. (2016). Hepatoprotective properties of dandelion: Recent update. Journal of Applied Pharmaceutical Science, 6(4), 202-205.

Domitrovic, R., Jakovac, H., Romic, Z., Rahelic, D., \& Tadic, Z. (2010). Antifibrotic activity of Taraxacum officinale root in carbon tetrachloride-induced liver damage in mice. Journal of Ethnopharmacology, 130(3), 569-577.

Edwards, C. A., \& Brien, W. D. (1980). Modified assay for determination of hydroxyproline in a tissue hydrolyzate. Clinica Chemica Acta, 104, 161-167.

Fortea, J. I., Fernández-Mena, C., Puerto, M., Ripoll, C., Almagro, J., Bañares, J., et al. (2018). Comparison of two protocols of carbon tetrachloride-induced cirrhosis in rats - Improving yield and reproducibility. Scientific Reports, 8(1), 9163.

Friedman, S. L. (2008). Hepatic fibrosis -- overview. Toxicology, 254(3), 120-129.

Gérard-Monnier, D., Erdelmeier, I., Régnard, K., Moze-Henry, N., Yadan, J.-C., \& Chaudiere, J. (1998). Reactions of 1-methyl-2-phenylindole with malondialdehyde and 4-hydroxyalkenals. Analytical applications to a colorimetric assay of lipid peroxidation. Chemical Research in Toxicology, $11(10), 1176-1183$.

Gonzalez-Castejon, M., Visioli, F., \& Rodriguez-Casado, A. (2012). Diverse biological activities of dandelion. Nutrition Reviews, 70(9), 534-547.

Gui, S.-Y., Wei, W., Wang, H., Wu, L., Sun, W.-Y., Chen, W.-B., et al. (2006). Effects and mechanisms of crude astragalosides fraction on liver fibrosis in rats. Journal of Ethnopharmacology, 103,154-159.

Hamza, A. A. (2010). Ameliorative effects of Moringa oleifera lam seed extract on liver fibrosis in rats. Food and Chemical Toxicology, 48(1), 345-355.

Hamza, A. A., Heeba, G. H., Elwy, H. M., Murali, C., El-Awady, R., \& Amin, A. (2018). Molecular characterization of the grape seeds extract's effect against chemically induced liver cancer: In vivo and in vitro analyses. Scientific Reports, 8(1), 1270. 
Higashi, T., Friedman, S. L., \& Hoshida, Y. (2017). Hepatic stellate cells as key target in liver fibrosis. Advanced Drug Delivery Reviews, 121, 27-42.

Hillegass, L., Griswold, D., Brickson, B., \& Albrightson-Winslow, C. (1990). Assessment of myeloperoxidase activity in whole rat kidney. Journal of Pharmacological Methods, 24(4), 285-295.

Jeon, D., Kim, S. J., \& Kim, H. S. (2017). Anti-inflammatory evaluation of the methanolic extract of Taraxacum officinale in LPS-stimulated human umbilical vein endothelial cells. BMC Complementary and Alternative Medicine, 17(1), 508.

Li, Q., Li, H. J., Xu, T., Du, H., Huan Gang, C. L., Fan, G., et al. (2018). Natural medicines used in the traditional Tibetan medical system for the treatment of liver diseases. Frontiers in Pharmacology, 9, 29.

Martinez, M., Poirrier, P., Chamy, R., Prufer, D., Schulze-Gronover, C., Jorquera, L., et al. (2015). Taraxacum officinale and related species-an ethnopharmacological review and its potential as a commercial medicinal plant. Journal of Ethnopharmacology, 169, 244-262.

Nandi, A., \& Chatterjee, I. (1988). Assay of superoxide dismutase activity in animal tissues. Journal of Biosciences, 13(3), 305-315.

Neha, Jaggi, A. S., \& Singh, N. (2016). Silymarin and its role in chronic diseases. Advances in experimental Medicine Biology, 929, 25-44.

Ni, M. M., Wang, Y. R., Wu, W. W., Xia, C. C., Zhang, Y. H., Xu, J., et al. (2018). Novel insights on notch signaling pathways in liver fibrosis. European Journal of Pharmacology, 826, 66-74.

Ovadje, P., Ammar, S., Guerrero, J. A., Arnason, J. T., \& Pandey, S. (2016). Dandelion root extract affects colorectal cancer proliferation and survival through the activation of multiple death signalling pathways. Oncotarget, 7(45), 7308073100 .

Park, C. M., Cha, Y. S., Youn, H. J., Cho, C. W., \& Song, Y. S. (2010). Amelioration of oxidative stress by dandelion extract through CYP2E1 suppression against acute liver injury induced by carbon tetrachloride in Sprague-Dawley rats. Phytotherapy Research, 24(9), 1347-1353.

Park, J. Y., Kim, J. J., Purck, C. M., Noh, K. H., \& Song, Y. S. (2007). Hepatopeotective activity of Taraxacum officinale water extract against D-galactosamineinduced hepatitis in rats. The FASEB Journal, 21, 847.847.

Peterson, G. L. (1977). A simplification of the protein assay method of Lowry et a which is more generally applicable. Analytical Biochemistry, 83, 346-356.

Rehman, G., Hamayun, M., Iqbal, A., Khan, S. A., Khan, H., Shehzad, A., et al. (2017). Effect of methanolic extract of dandelion roots on cancer cell lines and AMPactivated protein kinase pathway. Frontiers in Pharmacology, 8, 875

Reznick, A. Z., \& Packer, L. (1994). [38] Oxidative damage to proteins: Spectrophotometric method for carbonyl assay. In Methods in enzymology (Vol. 233, pp. 357-363): Elsevier.

Schutz, K., Carle, R., \& Schieber, A. (2006). Taraxacum--A review on its phytochemical and pharmacological profile. Journal of Ethnopharmacology, 107(3), 313-323.

Shay, J. E. S., \& Hamilton, J. P. (2018). Hepatic fibrosis: Avenues of investigation and clinical implications. Clin Liver Dis (Hoboken), 11(5), 111-114.

Singleton, V. L., Orthofer, R., \& Lamuela-Raventos, R. M. (1999). Analysis of total phenols and other oxidation substrates and antioxidants by means of folinciocalteu reagent. In L. Packer (Ed.), Methods in enzymology, (vol. 299, pp. 152-178). San Diego,London, New York, Tokyo: Academic Press,Harcourt Brace \& Company.

Varga, J., Brenner, D., \& Phan, S. H. (2005). Fibrosis research: Methods and protocols, (vol. 117). Totowa, New Jersey: Springer Science \& Business Media.

Wahid, B., Ali, A., Rafique, S., Saleem, K., Waqar, M., Wasim, M., et al. (2018). Role of altered immune cells in liver diseases: A review. Gastroenterología y Hepatología (English Edition), 41(6), 377-388.

Williams, C. A., Goldstone, F., \& Greenham, J. (1996). Flavonoids, cinnamic acids and coumarins from the different tissues and medicinal preparations of Taraxacum officinale. Phytochemistry, 42(1), 121-127.

\section{Publisher's Note}

Springer Nature remains neutral with regard to jurisdictional claims in published maps and institutional affiliations.

\section{Submit your manuscript to a SpringerOpen ${ }^{\odot}$ journal and benefit from:}

- Convenient online submission

- Rigorous peer review

- Open access: articles freely available online

- High visibility within the field

- Retaining the copyright to your article

Submit your next manuscript at $\boldsymbol{\nabla}$ springeropen.com 